\title{
Effect of caffeine on alertness of young healthy adults
}

\author{
${ }^{1}$ Dr. Pagar A. B, ${ }^{2}$ Dr. Raut S.E, ${ }^{3}$ Dr. Bhutada T.B
}

\section{Introduction}

An animal's ability to cope with the environmental changes depends on the integrity of cell communication and responses in terms of sensory perception and motor response ${ }^{1}$. Reaction time is an important parameter representing the integration of sensory, motor and coordination system of the body. It is the time interval between onset of stimulus and occurrence of response. This parameter is widely used in selection process of many occupations like pilots, car drivers and in industrial situation to prevent accidents. ${ }^{2,3}$ Determination of reaction time has important implications in sports physiology also. ${ }^{4}$

In today's fast-paced world of digital technology, every person works invariably in complex setups, where he is required to react to a variety of situations or changes in the external environment promptly and correctly and so also the medical student. So, present study is carried out to see the reaction time in healthy young medical students and effect of caffeine on it.

\section{Aim and objectives}

1. To find out reaction time in 30 male subjects before and after intake of caffeine.

2. To find out reaction time in 30 female subject before and after intake of caffeine.

3. To compare the reaction time in males and females.

4. To see the effect of caffeine consumption on reaction time in males and females.

\section{Material and method}

The study was conducted on 30 male and 30 female medical students (age group 20 to 25 years). Thorough general and systemic examination was carried out. Subjects having any major illness like or on treatment for hypertension, diabetes, kidney disease, any major auditory or visual defect including colour blindness were excluded from the study. Prior caffeine habits were taken in to consideration in the selection of subjects. Some of caffeine's response such as diminished rise in epinephrine with the acute administration of caffeine and the up regulation of adenosine receptors seem to be dampened by habitual intake. However, other effects of caffeine seem to be independent of habituation. For the present study subjects were accepted only if they reported a caffeine intake equal to less than two servings i.e. 200mg. In addition, all subjects were instructed to abstain from all caffeinated products for at least 24 hours prior to a scheduled test session.

All subjects were thoroughly acquainted with the operation of the apparatus. Beforeconducting the actual tests 10 practical sessions were given to each subject maintaining the experimental conditions with regards to the time and place of the test. Emphasis was laid on accuracy of response to minimize the error rate. Four practice trials were given each time before reading is taken.

One cup of coffee containing approximately $250 \mathrm{mg}$ of caffeine per cup was provided. Test was initiated half an hour after coffee consumption as it has been reported that peak levels may be obtained within 30 minutes after consumption. ${ }^{5}$

Recording of reaction time: ${ }^{6}$ Reaction time was measured by a simple machine, "Response analyser" by INCO, YantraShilpa system, Pune. This machine provides audio (low and high pitched) and visual (red, green and yellow colours) stimuli. The response is given by pressing a soft touch key with a thumb of dominant hand. It provides display range of $9.999 \mathrm{sec}$ with an accuracy of 1 millisecond. The reaction time was recorded in an isolated, adequately illuminated, noise free room between 4-6 pm. It was ensured that the location and direction of instrument as well as the subject is constant, so also the distance between them. The reaction time is measured as follows:

1. A ready signal was given to the subject.

2. Subject was asked to press the button with thumb of dominant hand as soon as he/she receives the stimulus.

3. Reaction time was displayed in milliseconds.

4. Five readings were taken for each stimulus by randomly varying the foreperiod (range $0-10 \mathrm{sec}$ )

5 . The mean of the above readings was taken as reaction time for that stimulus.

The subjects were assessed as mentioned above, before and 30 minutes after intake of caffeine. 


\section{Statistical analysis}

Student's Paired t test was applied to compare the RT before and after intake of caffeine. Unpaired t test was applied to compare the audio-visual RT between male and female subjects. A P value $<0.05$ is considered as significant.

\section{Results}

Table 1: Reaction time in males before $\&$ after consumption of caffeine.

\begin{tabular}{|l|l|l|l|l|}
\hline & $\begin{array}{l}\text { Before } \\
\text { Mean +- SD }\end{array}$ & $\begin{array}{l}\text { After } \\
\text { Mean +- SD }\end{array}$ & t-Value & P-Value \\
\hline VRT-R & $210.50+-3.27$ & $202.80+-3.02$ & $2.77366 \mathrm{E}-32$ & $<0.01$ \\
\hline VRT-G & $220.20+-1.71$ & $213.16+-1.70$ & $3.29067 \mathrm{E}-27$ & $<0.01$ \\
\hline VRT-Y & $233.03+-1.97$ & $226.36+-2.04$ & $3.40441 \mathrm{E}-28$ & $<0.01$ \\
\hline ART-L & $199.30+-2.26$ & $191.30+-2.13$ & $7.38343 \mathrm{E}-34$ & $<0.001$ \\
\hline ART-H & $194.63+-1.73$ & $184.43+-1.97$ & $9.5339 \mathrm{E}-19$ & $<0.001$ \\
\hline
\end{tabular}

Table 1 show that the Visual as well as Auditory reaction time decreases very significantly after intake of caffeine in males.

Table 2: Reaction time in females before \& after consumption of caffeine.

\begin{tabular}{|l|l|l|l|l|}
\hline & $\begin{array}{l}\text { Before } \\
\text { Mean +- SD }\end{array}$ & $\begin{array}{l}\text { After } \\
\text { Mean +- SD }\end{array}$ & t-Value & P-Value \\
\hline VRT-R & $216.50+-2.87$ & $208.30+-2.06$ & $5.85915 \mathrm{E}-25$ & $<0.001$ \\
\hline VRT-G & $227.10+-2.84$ & $221.16+-2.63$ & $4.88915 \mathrm{E}-17$ & $<0.001$ \\
\hline VRT-Y & $236.46+-3.15$ & $228.36+-3.20$ & $4.9865 \mathrm{E}-36$ & $<0.001$ \\
\hline ART-L & $204.50+-2.87$ & $197.00+-2.76$ & $5.39879 \mathrm{E}-36$ & $<0.001$ \\
\hline ART-H & $200.60+-3.02$ & $191.50+-3.00$ & $6.60006 \mathrm{E}-53$ & $<0.001$ \\
\hline
\end{tabular}

Table 2 show that the Visual as well as Auditory reaction time decreases very significantly after intake of caffeine in females.

Table 3 : Comparison of Reaction time in males \& females before consumption of caffeine.

\begin{tabular}{|l|l|l|l|l|}
\hline & $\begin{array}{l}\text { Male } \\
\text { Mean +-SD }\end{array}$ & $\begin{array}{l}\text { Female } \\
\text { Mean +-SD }\end{array}$ & t-Value & P-Value \\
\hline VRT-R & $210.50+-3.27$ & $216.50+-2.87$ & 0.295252666 & $>0.05$ \\
\hline VRT-G & $220.20+-1.71$ & $227.10+-2.84$ & 0.27677419 & $>0.05$ \\
\hline VRT-Y & $233.03+-1.97$ & $236.46+-3.15$ & 0.374645264 & $>0.05$ \\
\hline ART-L & $199.30+-2.26$ & $204.50+-2.87$ & 0.308589247 & $>0.05$ \\
\hline ART-H & $194.63+-1.73$ & $200.60+-3.02$ & 0.258869442 & $>0.05$ \\
\hline
\end{tabular}

Table 4 : Comparison of Reaction time in males \& females after consumption of caffeine.

\begin{tabular}{|l|l|l|l|l|}
\hline & $\begin{array}{l}\text { Male } \\
\text { Mean +- SD }\end{array}$ & $\begin{array}{l}\text { Female } \\
\text { Mean +- SD }\end{array}$ & t-Value & P-Value \\
\hline VRT-R & $202.80+-3.02$ & $208.30+-2.06$ & 0.311165763 & $>0.05$ \\
\hline VRT-G & $213.16+-1.70$ & $221.16+-2.63$ & 0.233765381 & $>0.05$ \\
\hline VRT-Y & $226.36+-2.04$ & $228.36+-3.20$ & 0.416840557 & $>0.05$ \\
\hline ART-L & $191.30+-2.13$ & $197.00+-2.76$ & 0.280936565 & $>0.05$ \\
\hline ART-H & $184.43+-1.97$ & $191.50+-3.00$ & 0.219780633 & $>0.05$ \\
\hline
\end{tabular}

Table $3 \& 4$ show that, males react faster than females though the results are not statistically significant.

\section{Discussion}

Cognitive function refers to an individual's ability to think and reason in terms of temporal and spatial relationships and in symbols such as words and number. Psychomotor function (sometimes called perceptual motor function) refers to an individual's ability to co-ordinate timely and appropriate responses to stimuli. Cognitive and psychomotor functions are not discrete; they overlap to the extent. Simple Reaction Time test is usually considered a psychomotor test.

In this study, the average values of the Visual and Auditory reaction times in both the sexes are slightly higher than the standard values.

Further, the auditory reaction times are faster than visual reaction times. Compared with the ear, the eye takes longer time to get its message started along the nerve to the brain. This probably accounts for the difference in the auditory and visual Reaction Times ${ }^{7}$.

Also, males reacted faster than females though our result is not statistically significant. Similar results were found in the studies conducted by Jack Botwinick and Larry ${ }^{8}$, Baker BL and Thomas $\mathrm{A}^{9}$ as well as Dixit TB, Amin MG and Pathak JD ${ }^{10}$.

Visual Reaction Time to Red light is faster as compared to Green and Yellow light in both the sexes. Same results were found by Shenvi\&Balasubramanian in 1994. This can be explained on the basis of the 
Trichromatic theory of colour vision. In study conducted by Tomita \& co-workers using microelectrode penetration of a single cone, it is found that $74 \%$ of units peaked in the Red spectrum, $16 \%$ in the Blue spectrum \&only $10 \%$ in the Green spectrum ${ }^{11,12,13}$. Cattell in 1887 found that Reaction time for Red and Green colour is almost similar whereas reaction time for yellow colour was more. ${ }^{14,15,16}$

In our study, we found that after 30 minutes of $250 \mathrm{mg}$ of caffeine consumption the Reaction Time to Auditory and Visual stimuli reduced very significantly in both Males and Females in all cases. Caffeine increased attention and vigilance by stimulating the CNS and also increases cortical arousal and perceptual sensitivity as has been reported by various studies. ${ }^{17}$ Caffeine particularly has a profound effect on the central nervous system. Caffeine produces more rapid, clearer flow of thought, allays drowsiness and fatigue, and increases the capability of a greater sustained intellectual effort and more perfect association of ideas. It also causes a keener appreciation of sensory stimuli and reaction time is diminished. All this occurs at doses of 150$250 \mathrm{mg}$ of caffeine. ${ }^{18}$

Study showing the effect of caffeine on energetic arousal found that caffeinated beverages stimulate autonomic nervous system and increase alertness. ${ }^{19}$ Brice in 2002 studied the effects of caffeine on mood and performance. Caffeine lead to an increased alertness and anxiety and improved performance. ${ }^{20}$ Yeoman's demonstrated that the effects of caffeine on mood and performance depend on the level of caffeine abstinence. Caffeine reliably improved performance on a sustained attention task and increased mental alertness in moderate coffee consumers who were tested when caffeine deprived. ${ }^{21}$

Although we got these results, we recognize that we should estimate our results carefully, because of some limitations. 1) Actual blood level of caffeine was not tested. 2) Effect of regular, long term consumption of caffeine on Reaction time was not assessed.

\section{Conclusion}

Males are faster than females though statistically not significant. The Auditory Reaction Time was less compared to Visual Reaction Time in both males and females. The Reaction Time after caffeine consumption was significantly decreased in both males and females. This may be because caffeine increases attention and vigilance by stimulating the central nervous system and also increases cortical arousal and perceptual sensitivity.

\section{References}

[1]. Parekh N, Gajbhiye IPR, Wahane M, Titus J. The Study of Auditory and Visual Reaction Time in Healthy Control, Patients of Diabetes Mellitus on Modern Allopathic Treatment, and those Performing Aerobic Exercises. J Indian AcadClin Med 2004; 5(3):239-243.

[2]. Lally N, Nettlbeck T. Intelligance, reaction time and inspection time. American J of Mental Deficiency. 1977; 82: $273-81$.

[3]. Mathur LA, Tendon HB. Reaction time experiments. Journal of abnormal psychology. 1964;72:35-40

[4]. Chakraborty, Ghosh and Sahana. Physiological aspects of yogi's discipline. In Ghost HN Ed 2 Human Physiology, Calcutta: New Bookstall, 1984:1234-1235.

[5]. Barraclough, M.S., and Beech, J.R. Effects of caffeine on functional asymmetry in aposner letter-recognition task. Pharmacology, Biochemistry and Behavior, 1995; 52:731-735.

[6]. Jensen AR. Learning and Reaction time - Educability and Group differences. Harper and Row. New York 1973 : 69-90.

[7]. Woodworth and Schlosberg-Distraction. Experimental Psychology, pp-84-90.

[8]. Jack Botwinick and Larry. Thompson. Components of Reaction Time in relation to Age and Sex. The Journal of Genetic Psychology, 1966; 108: 175-183.

[9]. Blaine L. Baker and Thomas A. Jones. Age and Sex parameters in psychomotor Learning. Perceptual and Motor skills, 1964; 19:935-945.

[10]. Dixit, T. B, Amin, M. G and Pathak, J. D. Assessment of Mental Alertness after various Phenothiazines. Journal of Indian Medical Association, 1964; 42: 173-175.

[11]. Best and Taylor Physiological Basis of Medical Practice. 11th Edition. Pp420-421.

[12]. Devalios R. L. Central mechanisms of color vision. Handbook of sensory Physiology vol. V11/3A: Central Visual Information, edited by R. Jung Heidelberg, FRG: Springer, 1973: 209-253.

[13]. Devalios. R. L. Color vision mechanisms in Monkey. Journal of General Physiology, 1960; 43:115-128.

[14]. Cattell, J.MCkMind.1886; 11; 63-65:220-242,377-392,524-538.

[15]. Cattell, J.MckMind.1887; 2:68-74.

[16]. Cattell, J.Mck. Philos.studies.1888; 4:241-250.

[17]. Avram Goldstein, Sophiakaizer and Richard warren. Psychotropic effects of caffeine in man. Alertness, Psychomotor co-ordination and Mood. The Journal of Pharmacology and Experimental Therapeutics, 1965; 150(1): 146-151.

[18]. Stephenson.P.E.Physiologic and psychotropic effects of caffeine on man. Journal.Am.Dietetic Association1977; 71:240.

[19]. QuinlanP. T, LaneJ, Moore. I, AspenJ, RycroftJ. A, O'Brien D. C. The acute physiological and mood effects of tea and coffee: The role of Caffeine level. Pharmacology. BiochemicalBehaviour, 2000; 66(1): 19-28.

[20]. BriceC. F, Smith A. P. Effects of caffeine on Mood and performance: A study of realistic consumption. Psychopharmacology (Berlin) 2002; 164(2): 188-192.

[21]. Yeoman's M. R, Ripley T, Davies L. H, Rusted J, M, Rogans P. J. Effects of Caffeine on performance and mood depend on the level of caffeine abstinence. Psychopharmacology (Berlin) 2002; 164(3): 241-249. 